\title{
A prospective randomized study comparing $0.5 \%$ isobaric solutions of levobupivacaine and ropivacaine with fentanyl as an adjuvant for subarachnoid block in patients undergoing elective lower limb surgery
}

\author{
Suchitha Kamath ${ }^{1, *}$, Manjunath K. Kamath ${ }^{2}$, Ananda Bangera ${ }^{3}$ \\ ${ }^{1}$ PG Student, ${ }^{2}$ Additional Professor, ${ }^{3}$ HOD, K. S. Hegde Medical Academy, Mangalore, Karnataka, India
}

*Corresponding Author:

Email: suchithakamath@gmail.com

Received: $09^{\text {th }}$ May, 2017

Accepted: $06^{\text {th }}$ June, 2017

\begin{abstract}
In the present study we compared levobupivacaine with ropivacaine in order to determine the suitability of each drug for spinal anaesthesia.

Aim: To compare levobupivacaine with ropivacaine with respect to onset, duration and regression of motor and sensory blockade. This prospective randomized double blinded study was conducted in 100 patients who were randomly assigned to one of the 2 study groups of 50 patients each. The first group was given $2.5 \mathrm{ml}$ levobupivacaine with $0.5 \mathrm{ml}$ fentanyl and second group was given $2.5 \mathrm{ml}$ of ropivacaine with $0.5 \mathrm{ml}$ of fentanyl for spinal anaesthesia.

Statistical analysis: Observation obtained both the groups were recorded and tabulated. Analysis was carried out using student's $\mathrm{t}$ test, fischers exact test and chi- square test.

Results: Levobupivacaine-fentanyl group had delayed onset of motor and sensory blockade. Ropivacaine-fentanyl group had faster onset and regression of motor and sensory blockade.

Conclusion: Ropivacaine-fentanyl combination is a better option when compared to levobupivacaine - fentanyl combination for use in short surgical procedures due to its faster onset of action, early regression of blockade as well as higher success rate.
\end{abstract}

Keywords: Fentanyl, Levobupivacaine, Ropivacaine, Spinal anesthesia.

\section{Introduction}

Neuraxial anesthesia has greatly expanded the anaesthesiologist's armamentarium. Spinal anaesthesia is distinguished by its ease of performance, cost effectiveness, safety, quick onset of action, good muscle relaxation and reduced blood loss. ${ }^{1}$ The patient will be conscious and able to protect his airway, it minimizes the need for airway manipulation, reduces chances of aspiration, reduces postoperative morbidity, incidence of deep vein thrombosis, pulmonary embolism and pneumonia. ${ }^{2}$

As the current practice of medicine focuses on outpatient care, spinal anaesthetics used should provide short acting and adequate anaesthesia without compromising early ambulation and discharge from the day surgery.

Levobupivacaine and ropivacaine are two new long-acting local anaesthetics (LA) which have been developed as an alternative to bupivacaine in order to offer a safer alternative to bupivacaine. They have the desirable blocking properties of racemic bupivacaine along with a greater margin of safety due to their reduced toxic potential. ${ }^{3}$

Neuraxial opioids are widely used as adjuncts with LAs as they allow lower dose of LAs. They improve the quality of intraoperative analgesia and prolong the duration of analgesia without compromising its benefits such as early mobilization and early voiding.
The addition of fentanyl along with levobupivacaine and ropivacaine for spinal anaesthesia has been shown to prolong the duration of analgesia in the early postoperative period and thereby improving the quality of anaesthesia. ${ }^{4,5}$

\section{Materials and Methods}

This study was approved by the institutional ethics committee. Written informed consent was obtained from 100 patients who fulfilled the following inclusion criteria: Adults aged 18-65 years posted for elective lower limb surgeries under spinal anaesthesia, ASA physical status I and II. Patients having absolute contraindications for spinal anaesthesia, emergency surgeries, mentally impaired patients, patients with known hypersensitivity of the drugs that were used in the study, patients with BMI more than $30 \mathrm{~kg} / \mathrm{m}^{2}$ and height less than $150 \mathrm{~cm}$, pregnancy, patients with spine deformities, surgeries that lasted for $>3 \mathrm{hrs}$, all cases of technical failure were excluded.

This study was conducted in the form of a prospective, randomized, double-blind, controlled fashion. The patients were randomized by closed envelope method into two groups: Group A ( $n=50$, levobupivacaine group) patients were administered $2.5 \mathrm{ml}(12.5 \mathrm{mg})$ of $0.5 \%$ isobaric levobupivacaine with $0.5 \mathrm{ml}$ of $25 \mu \mathrm{g}$ fentanyl intrathecally. Group B ( $\mathrm{n}=50$, ropivacaine group) patients were administered $2.5 \mathrm{ml}$ 
(12.5mg) of $0.5 \%$ isobaric ropivacaine with $0.5 \mathrm{ml}$ of $25 \mu \mathrm{g}$ fentanyl intrathecally.

Pre-anaesthetic evaluation was carried out on all patients and was informed about the nature of the study and anaesthetic technique. All patients were educated about the Visual Analogue Scale (VAS) and were told to point out the intensity of pain on the scale. A written informed consent was taken. Patients were kept nil per oral as per the standard guidelines. All patients were premedicated with tablet diazepam $5 \mathrm{mg}$ (if weight of the patient was less than or equal to $50 \mathrm{~kg}$ ) or $10 \mathrm{mg}$ (if weight of the patient was more than $50 \mathrm{~kg}$ ) and tablet ranitidine $150 \mathrm{mg}$ orally both 12 hours and 2 hours before surgery. In the operation theatre monitors like electrocardiography, non invasive blood pressure (NIBP), pulse oximetry were connected and baseline values of heart rate (HR), blood pressure (BP) and oxygen saturation (SPO2) were noted. Intravenous access was secured using an $18 \mathrm{G}$ IV cannula and $500 \mathrm{ml}$ of ringer lactate infusion was started. With patient in sitting position, subarachnoid block was performed under aseptic precautions by an anaesthesiologist with $25 \mathrm{G}$ Quincke Babcock spinal needle at $\mathrm{L}_{3}-\mathrm{L}_{4}$ lumbar space and $3 \mathrm{ml}$ of the test solution was loaded and injected. Patient was then placed in supine position immediately. Oxygen $(4 \mathrm{l} / \mathrm{min})$ was supplemented through a facemask.

The anesthesiologist was blinded to the intrathecally administered solution. The following observations were made: HR, NIBP, saturation were recorded initially for every $2 \mathrm{~min}$ for the 1 st $10 \mathrm{~min}$. Then monitoring was done every $5 \mathrm{~min}$ for next $10 \mathrm{~min}$ and every $15 \mathrm{~min}$ till 3 hours or till the completion of surgery whichever is earlier. Sensory block was assessed at $T_{10}$ level with ice or wasp of cotton every 2 min for the first $10 \mathrm{~min}$, every $5 \mathrm{~min}$ for next $10 \mathrm{~min}$ and then every $15 \mathrm{~min}$ till the end of the surgery. Time taken for T10 level of blockade, peak level of blockade achieved and its time taken were noted. Motor blockade was assessed with modified Bromage score every 2 min till the onset of complete motor blockade. Onset time for complete motor blockade (Grade IV) was noted.

Intraoperative complications like bradycardia and hypotension were looked for and treated accordingly. The level of sensory blockade and degree of motor blockade were noted after the completion of surgery.

In the post-operative ward, motor blockade was monitored every $15 \mathrm{~min}$ till the Bromage scale was grade 0 and sensory block regressed to $S_{1}$ so that patient could be mobilized or till they required rescue analgesic agent. Post-operative findings like duration of analgesia, time for return of sensory and motor function were noted and compared between the two groups and tabulated for analysis. Patient satisfaction was noted by VAS. Analgesics were administered only on demand by the patients. Injection tramadol $50 \mathrm{mg}$ intravenous (IV) was given at patient's first request for analgesia.
The duration of sensory block, time to the first request for analgesia, duration of analgesia and occurrence of side effects were noted. Monitoring was continued till complete recovery from motor blockade (Grade I in Bromage scale) and regression of sensory block to S2. Duration of sensory blockade was defined as the period from the time of intrathecal injection of the drug to regression of blockade to S2 level. Duration of motor blockade was the time taken from the time of injection till the subject attains complete motor recovery, Bromage-0. Duration of complete analgesia was defined as the time from the intrathecal injection to VAS score $>0$.

\section{Results}

The groups were comparable in terms of demographic data, ASA grading, type of surgeries and duration of anaesthesia. [Table 1]

Hemodynamic variables were compared between 2 groups. Heart rate values were statistically significant at $35 \mathrm{~min}, 50 \mathrm{~min}$ and $65 \mathrm{~min}$ but were not significant clinically. (Fig. 1)

Systolic blood pressure values were statistically significant at $4 \mathrm{~min}, 6 \mathrm{~min}, 15 \mathrm{~min}, 20 \mathrm{~min}, 35 \mathrm{~min}, 50$ $\mathrm{min}$ and $65 \mathrm{~min}$ but were not significant clinically. (Fig. 2)

Diastolic blood pressure was compared between 2 groups and no statistically significant values were found at all intervals. (Fig. 3)

The mean time to onset of motor blockade in Group A (levobupivacaine-fentanyl group) $8.8485 \pm 1.73424$ and in Group B (ropivacaine-fentanyl group) was $5.4043 \pm 1.37777$ was found to be statistically significant. The onset of motor blockade was found to be significantly prolonged in Group A (levobupivacaine-fentanyl group). (Fig. 4)

The onset time for $\mathrm{T}_{10}$ sensory blockade in group $\mathrm{A}$ (levobupivacaine-fentanyl group) was $5.697 \pm 1.74078$ min and group B (ropivacaine-fentanyl group) was $3.3617 \pm 1.25846 \mathrm{~min}$ and was found to be statistically significant ( $\mathrm{p}$ value $<0.001$ ). The onset of sensory blockade was relatively faster in ropivacaine-fentanyl group as compared to the levobupivacaine-fentanyl group. (Fig. 5)

The onset time to peak level of sensory blockade in group A was $7.15 \pm 1.805 \mathrm{~min}$ and in group B was $5.7 \pm 1.25 \mathrm{~min}$ and was found to be statistically significant ( $\mathrm{p}$ value $<0.001$ ).

The maximum level of blockade in group $\mathrm{A}$ was $\mathrm{T}_{8}$ and that in group B was $\mathrm{T}_{6}$ (Fig. 6)

The time taken for complete regression of motor blockade in group A was $180.90 \pm 32.24$ min and in group B was $162.12 \pm 43.63 \mathrm{~min}$. It was found to be statistically significant ( $p$ value 0.03 ). The duration of motor blockade was more in levobupivacaine - fentanyl group as compared to ropivacaine - fentanyl group. (Fig. 7) 
The time taken for regression of sensory blockade to $S_{1}$ level in group A was $242.72 \pm 47.64 \mathrm{~min}$ and in group B was $176.80 \pm 32.03 \mathrm{~min}$ which was found to be statistically significant ( $\mathrm{p}$ value $<0.001)$. The sensory blockade was significantly prolonged in levobupivacaine - fentanyl group as compared to the ropivacaine - fentanyl group. (Fig. 8)

The time to rescue analgesia found to be $334.22 \pm$ $29.57 \mathrm{~min}$ in group A and $261.38 \pm 23.58 \mathrm{~min}$ in group
B. It was found to be statistically significant ( $\mathrm{p}$ value $<0.001$ ). It was found that time to rescue analgesia was prolonged in levobupivacaine - fentanyl group when compared to ropivacaine - fentanyl group. (Fig. 9)

The failure rates were found to be extremely statistically significant ( $p$ value $<0.0001$ ). in our study high failure rates were seen in levobupivacaine fentanyl group for the reasons unknown. (Fig. 10)

Table 1: Demographic Data

\begin{tabular}{|l|c|c|}
\hline & Group A & Group B \\
\hline Age (Years) & $38.18 \pm 13.417$ & $38.38 \pm 12.133$ \\
\hline Sex (M/F) & $39 / 10$ & $32 / 15$ \\
\hline ASA I/II & $40 / 9$ & $39 / 8$ \\
\hline Duration Of Surgery (MIN) & $80.91 \pm 29.986$ & $97.7 \pm 29.696$ \\
\hline
\end{tabular}

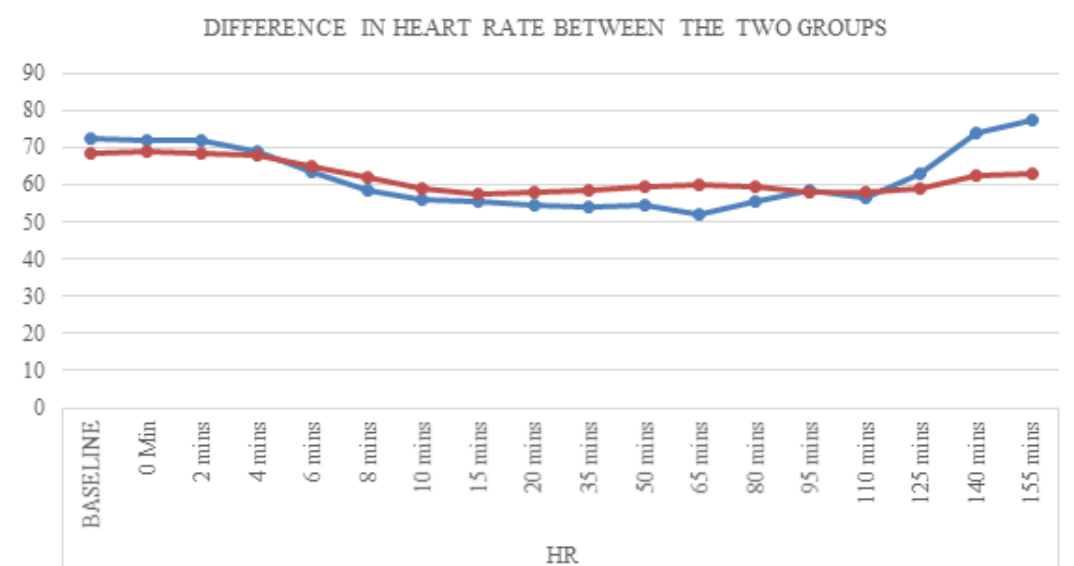

$\multimap$ GROUP A $\multimap$ GROUP B

Fig. 1: Comparison of heart rate between 2 groups

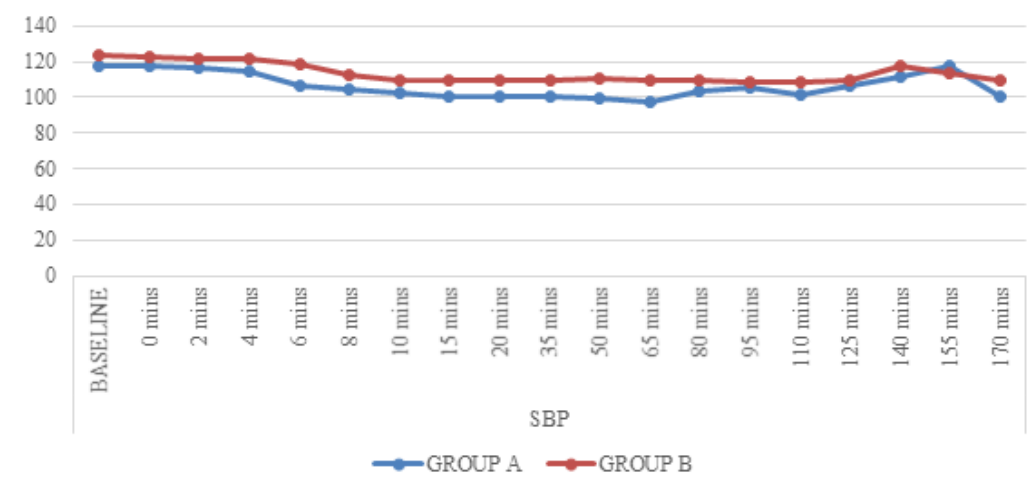

Fig. 2: Comparison of systolic blood pressure between 2 groups 


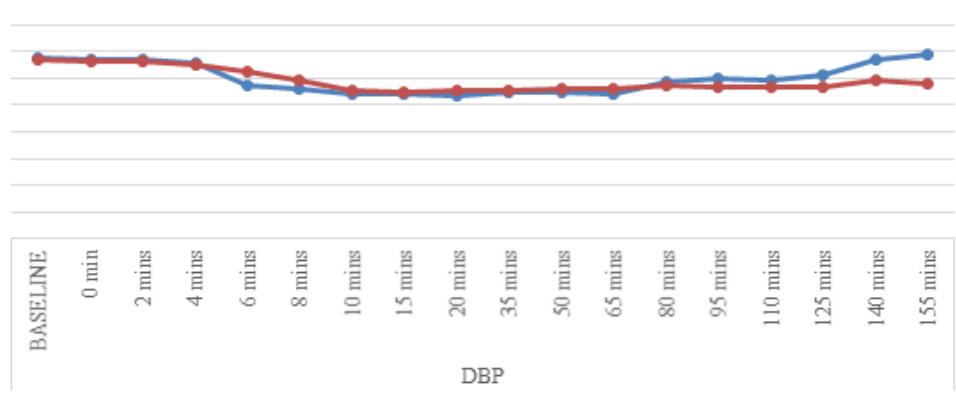

$\multimap$ GROUP A $\multimap$ GROUP B

Fig. 3: Comparison of diastolic blood pressure between 2 groups

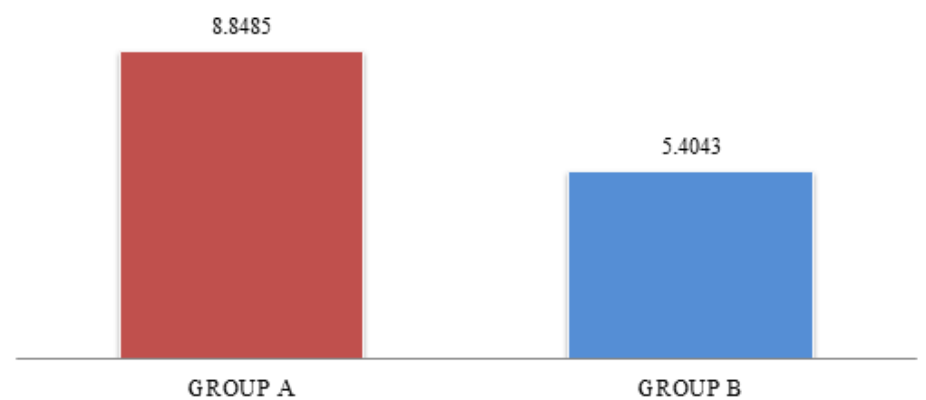

Fig. 4: Comparison of onset of motor blockade



Fig. 5: Comparison of onset time for $\mathrm{t}_{10}$ sensory blockade



Fig. 6: Onset time for peak sensory blockade 




GROUP A

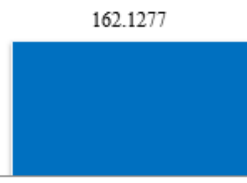

GROUP B

Fig. 7: Comparison of time to recovery of motor blockade



GROUP A

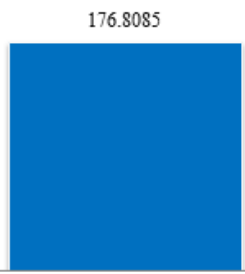

GROUP B

Fig. 8: Comparison of time to $s_{1}$ regression

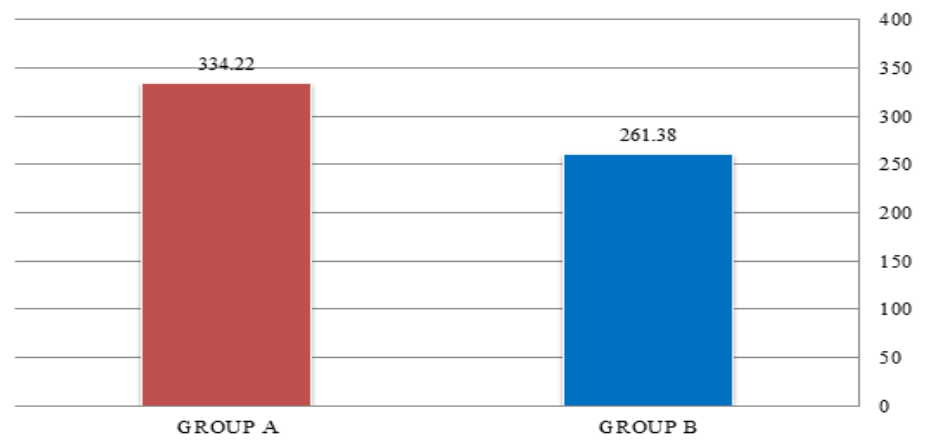

Fig. 9: Time to rescue analgesia

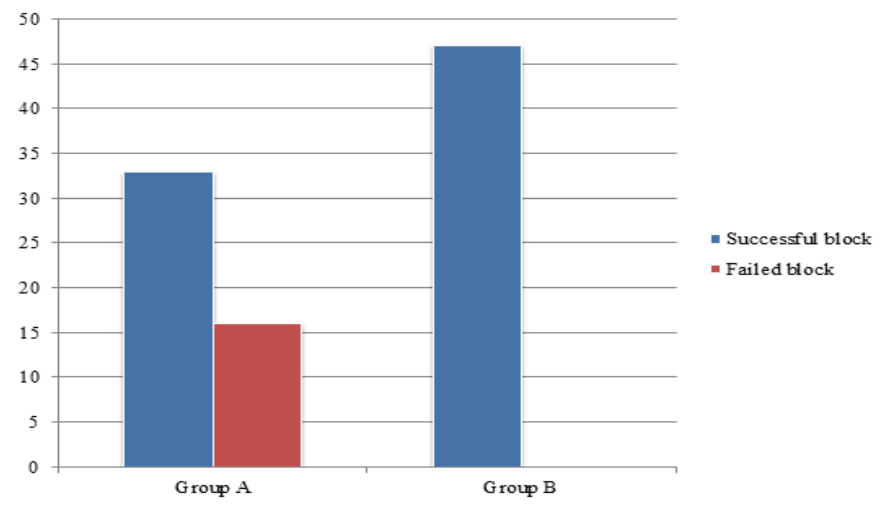

Fig. 10: Failure rates 


\section{Discussion}

Spinal anaesthesia is an ideal choice for lower limb surgeries. It is being widely used in clinical practice but is often associated with intraoperative hypotension, bradycardia and postoperative residual motor blockade which is not desirable for the patient. Agents that offer hemodynamic stability, effective and prolonged postoperative analgesia along with early ambulation and recovery are essential to provide optimum care to the patient.

Hyperbaric bupivacaine is the most popular among all drugs being used for spinal anaesthesia but it is associated with problems like prolonged motor blockade, cardiac and neurotoxic effects which led to the development of newer and safer congeners of bupivacaine like ropivacaine and levobupivacaine.

Ropivacaine is an S enantiomer of bupivacaine. It has low lipid solubility and blocks nerve fibers involved in pain transmission ( $\mathrm{A} \delta$ and $\mathrm{C}$ fibers) to a greater degree as compared to those controlling motor functions (A $\beta$ fibers). ${ }^{6}$ In various studies, it has been shown that ropivacaine provides hemodynamic stability, shorter duration of motor block which is a desirable feature for early ambulation, voiding, and physiotherapy. ${ }^{7}$ Levobupivacaine is a pure $\mathrm{S}$ enantiomer of bupivacaine. Various studies have reported that levobupivacaine results in clinical profile of spinal block undistinguishable from that of racemic bupivacaine. ${ }^{8}$ It produces similar hemodynamic changes as that of bupivacaine.

But it is essential to intensify and prolong the duration of sensory block without increasing the duration of motor block, thus prolonging the duration of postoperative analgesia. Opioids like fentanyl possess synergistic analgesic effect with local anaesthetics when administered intrathecally. They help to improve the quality of intra-operative analgesia \& enhance benefits such as early mobilization.

So this study is done to compare the efficacy of levobupivacaine-fentanyl and ropivacaine-fentanyl in subarachnoid block for lower limb surgeries.

We compared both groups with respect to age, sex, ASA physical status and duration of surgery. Four patients (one from Group A and three from Group B) had to be excluded from the study as the duration of surgery lasted for more than 3 hours (exclusion criteria of the study).

Age, sex, ASA physical status comparison showed no statistical significance between the two groups. The duration of surgery was compared between two groups and it was found to be statistically significant but was not clinically significant as only surgeries lasted less than 3 hours duration were included in the study.

The baseline hemodynamic characteristics like heart rate, systolic blood pressure and diastolic blood pressure were comparable between the two groups.

The baseline heart rate in Group A (levobupivacaine-fentanyl) was $72.24 \pm 16.619$ beats/min and Group B (ropivacaine-fentanyl) was $68.6 \pm 10.24$ beats $/ \mathrm{min}$. The difference between the two groups were found to be statistically significant at 35 $\mathrm{min}, 50 \mathrm{~min}$ and $65 \mathrm{~min}$ but were not significant clinically. There was no significant drop in heart rate in either of the groups.

Systolic blood pressure were compared between the two groups and were found statistically significant at few intervals like $4 \mathrm{~min}, 6 \mathrm{~min}, 8 \mathrm{~min}, 10 \mathrm{~min}, 15$ min, $20 \mathrm{~min}, 35 \mathrm{~min}, 50 \mathrm{~min}$ and $65 \mathrm{~min}$ but were clinically not significant as there was no significant drop in blood pressure in either of the two groups. Diastolic blood pressure measurement at all intervals was found to be statistically insignificant. No patients had hypotension in levobupivacaine-fentanyl group. Two (4\%) patients developed hypotension in ropivacaine-fentanyl group which was treated with Inj. mephentermine $6 \mathrm{mg}$ IV. This was found to be statistically insignificant. No episodes of bradycardia were found in either of the groups.

Mehta et $\mathrm{al}^{7}$ conducted a study on comparative evaluation of intrathecal administration of newer local anaesthetic agents levobupivacaine and ropivacaine with bupivacaine in 75 patients undergoing lower limb surgery. In this study, $8 \%$ of the patients in each group developed hypotension. In our study, we had only $4 \%$ of the patients belonging to ropivacaine-fentanyl group developed hypotension and no patients in levobupivacaine-fentanyl group developed hypotension. Their study showed following observations: the onset of motor blockade in levobupivacaine group was $5.46 \pm 1.72 \mathrm{~min}$ and in ropivacaine group was $6.46 \pm 1.14$ min, the onset of sensory block was $4.38 \pm 1.53 \mathrm{~min}$ in levobupivacaine group and $5.45 \pm 1.00 \mathrm{~min}$ in ropivacaine group, the duration of sensory blockade was $189.4 \pm 42.9 \mathrm{~min}$ in levobupivacaine group and $144.32 \pm 32.1 \mathrm{~min}$ in ropivacaine group, the duration of motor blockade in levobupivacaine group was $172.76 \pm 38.9 \mathrm{~min}$ and in ropivacaine group was $128.24 \pm 29.1 \mathrm{~min}$. Comparing our study to the above study we found that, onset of motor blockade in levobupivacaine-fentanyl group was significantly prolonged when compared to ropivacaine-fentanyl group. The onset of sensory block to $\mathrm{T}_{10}$ was delayed in levobupivacaine-fentanyl group when compared to ropivacaine-fentanyl group. The duration of sensory blockade ( $S_{1}$ regression) and motor blockade in levobupivacaine-fentanyl group was prolonged when compared to ropivacaine-fentanyl group. Therefore we can say that ropivacaine-fentanyl provides faster onset of motor and sensory blockade, comparable duration of motor and sensory blockade whereas levobupivacainefentanyl has significant delay in onset of motor and sensory blockade but prolonged motor and sensory blockade which might interfere with early ambulation and postoperative recovery.

Akan et $\mathrm{al}^{9}$ compared effects of levobupivacaine alone and in combination with fentanyl and sufentanil 
in 60 patients undergoing TURP. $10.5 \%$ patients developed hypotension in levobupivacaine-fentanyl group, whereas in our study no patients in levobupivacaine-fentanyl group developed hypotension. Bradycardia developed in $10.5 \%$ in levobupivacainefentanyl group; in contrast in our study no patients in levobupivacaine-fentanyl group had bradycardia. Time to $\mathrm{T}_{10}$ sensory blockade was $6.9 \pm 1.7 \mathrm{~min}$ in levobupivacaine-fentanyl group which was comparable to that found in our study. The maximum sensory blockade attained in all 3 groups was $\mathrm{T}_{8}$ which is comparable to the finding our study. The duration of motor blockade in levobupivacaine-fentanyl group was $100.0 \pm 21.8 \mathrm{~min}$; in contrast our study finding was significant prolongation of motor blockade in levobupivacaine-fentanyl group. Time to first request for analgesia in lin levobupivacaine-fentanyl group was $310 \pm 47.6$ min which was comparable to that in our study.

Jagtap et $\mathrm{al}^{10}$ in their study on 60 patients scheduled for major lower limb orthopedic surgery where they compared the effects of intrathecal ropivacaine-fentanyl (RF) and bupivacaine-fentanyl (BF), observed that hypotension occurred in $1(3.3 \%)$ patient in Group RF as compared to our study where there were no significant hemodynamic changes in ropivacaine-fentanyl group. 2(4\%) patients developed hypotension in ropivacaine-fentanyl group which was statistically insignificant. No patients developed bradycardia in our study. 1 patient ropivacaine-fentanyl group in their study developed shivering whereas in our study 2 patients in ropivacaine-fentanyl group developed shivering, which was treated with inj.tramadol $50 \mathrm{mg}$ IV. One patient in our study in ropivacaine-fentanyl group had high spinal $\left(\mathrm{T}_{4}\right)$ which was managed appropriately. The highest sensory blockade attained was $T_{6}$ which was comparable to that in our study with ropivacaine-fentanyl group. Characteristics of sensory and motor blockade in the above study were: time to reach peak sensory level in $\mathrm{RF}$ group was $6.86 \pm 3.73 \mathrm{~min}$, time to reach peak motor block in RF group was $6.02 \pm 2.1 \mathrm{~min}$, time to sensory regression in group RF was $226 \pm 46.98 \mathrm{~min}$, time for motor regression in group RF was $242 \pm 47.06$ min, time rescue analgesia in group RF was $234.44 \pm 58.76 \mathrm{~min}$. Comparing these results with our study, we found that ropivacaine-fentanyl had faster onset and faster regression of motor blockade. Time to reach peak motor blockade and time to rescue analgesia were comparable with the above study. Time to reach peak sensory level and time to sensory regression to $S_{1}$ was also comparable with the above study. Thus we can say that ropivacaine-fentanyl has faster onset of motor and sensory blockade and faster regression of sensory and blockade therefore an ideal choice for day care patients.

Unlike the observations found in other studies, our study we found high failure rates in levobupivacainefentanyl group which was extremely statistically significant. Various reasons for failed spinal anaesthesia like: technical errors such as difficult positioning, failed lumbar puncture, misplaced intrathecal injection, solution injection errors like inappropriate dose selection, loss of injectate, chemical incompatibility, use of inactive and expired local anaesthetic solutions were all ruled out. ${ }^{11}$ All cases the drug was administered after confirming free flow of CSF, despite of which there was failed block. The minimum local anaesthetic dose of levobupivacaine was found to be $11.7 \mathrm{mg}^{12}$ and in our study we used $12.5 \mathrm{mg}$ of levobupivacaine which is far above the minimum local anaesthetic dose. Fentanyl and levobupivacaine combination is found to act synergistically ${ }^{13}$ and therefore addition of fentanyl to levobupivacaine cannot lead to failure of spinal anaesthesia. We also changed various drug batches of levobupivacaine but in vain. All the failures with levobupivacaine-fentanyl, repeat spinal was given with hyperbaric bupivacaine. The reason for high failure rates with levobupivacaine remained to be inconclusive.

\section{Conclusion}

Our study has shown that levobupivacaine-fentanyl group had delayed onset of motor and sensory blockade. On the other hand, ropivacaine-fentanyl group had faster onset of motor and sensory blockade. Also, there was faster regression of both sensory and motor blockade in ropivacaine group when compared to levobupivacaine group making it a better spinal anaesthetic for outpatient anaesthesia.

Therefore, we conclude that ropivacaine-fentanyl combination is a better option when compared to levobupivacaine - fentanyl combination for use in short surgical procedures, especially lower limb surgeries due to its faster onset of action, early regression of blockade as well as higher success rate. However, in terms of intensity of motor and sensory blockade, both are similar.

\section{References}

1. Brull R, Macfarlane AJR, Chan VWS. Spinal, epidural and caudal anaesthesia. Miller RD, Cohen NH, Erikson LI, Fleisher LA, Wiener JP, Young WL. Miller's Anesthesia. 8th ed. United States of America: Elsevier; 2014. p. 1684-720.

2. Rodgers A, Walker N, Schug S, McKee A, Kehlet H, van Zundert A, et al. Reduction of postoperative mortality and morbidity with epidural or spinal anaesthesia: results from overview of randomized trials. BMJ. 2000;321(7275):1493.

3. Leone S, Cianni SD, Casati A, Fanelli G. Pharmacology, toxicology, and clinical use of new long acting local anesthetics, ropivacaine and levobupivacaine. Acta Biomed. 2008;79:92-105.

4. Chaudhary A, Bogra J, Verma R. Efficacy of spinal ropivacaine versus ropivacaine with fentanyl in transurethral resection operations. Saudi Journal of Anaesthesia. 2014;8(1):88-91.

5. Girgin NK, Gurbet A, Turker G, Bulut T, Demir S, Kilic N, et al. The Combination of low-dose 
levobupivacaine and fentanyl for spinal anaesthesia in ambulatory inguinal herniorrhaphy. The Journal of International Medical Research. 2008;36:1287-292.

6. Kuthiala G, Chaudhary G. Ropivacaine: A review of its pharmacology and clinical use. Indian Journal of Anaesthesia. 2011;55(2):104-10.

7. Mehta A, Gupta V, Wakhloo R, Gupta N, Gupta A, Bakshi R, et al. Comparative evaluation of intrathecal administration of newer local anaesthetic agents Ropivacaine and Levobupivacaine with Bupivacaine in patients undergoing lower limb surgery. Internet journal of anaesthesiology. 17(1). Citation: http://ispub.com/IJA/17/1/9270.

8. Glaser C, Marhofer P, Zimpfer G, Heinz MT, Sitzwohl C, Kapral S,et al. Levobupivacine versus racemic bupivacaine for spinal anesthesia. AnesthAnalg. 2002. 94:194-8.

9. Akan B, Yagan O, Bilal B, Erdem D, Gogus N. Comparison of levobupivacaine alone and in combination with fentanyl and sufentanil in patients undergoing transurethral resection of prostrate. Journal of Research in Medical Sciences. 2013;18:378-382.

10. Jagtap S, Chhabra A, Dawoodi S, Jain A. Comparison of intrathecal ropivacaine-fentanyl and bupivacainefentanyl for major lower limb orthopaedic surgery: A randomized double-blind study. Indian Journal of Anaesthesia. 2014;58(4):442-6.

11. Gautier P, DeKock M, Huberty L, Demir T, Izydorczic $\mathrm{M}$, Vanderick B. Comparison of effects of ropivacaine, levobupivacine and bupivacaine for caesarean section. Br journal of anaesthesia. 2003;91(5):684-9.

12. Sell A, Olkkola KT, Jalonen J, Aantaa R. Minimum effective local anaesthetic dose of isobaric levobupivacaine and ropivacaine administered via a spinal catheter for hip replacement surgery. $\mathrm{Br} \mathrm{J}$ Anaesth. 2005;94:239-42.

13. Christiansson L. Update on adjuvants in regional anaesthesia. Periodicumbiologorum. 2009;111(2):161170. 